\title{
Management of stress among primary school teachers in Ismailia city. An intervention study
}

\author{
Fatma A. Meky, Amani Wahid, ${ }^{* *}$ Amira Gamal, ${ }^{* *}$ and Yasser Youssef** \\ *Department of Community, Environmental and Occupational Medicine, Ain Shams \\ University, Faculty of Medicine \\ ** Department of Public Health, Community Medicine, Environmental Medicine and \\ Occupational Medicine, Suez Canal University, Ismailia, Egypt,
}

\begin{abstract}
Teacher stress is a multifactorial phenomenon that spread globally irrespective to the level of development of country. Aim of study: The aim of this study was to measure the efficacy of a stress management program in lowering the level of stress among schools' teachers who suffers work-related stress. Subjects and Methods: A quasi-experimental design was used to test the effect of application of stress management program among primary school teachers living in Ismailia city. Cluster sampling technique was used to choose the primary schools included in the study. A sample size of 170 school teachers was selected randomly from the chosen schools. A self administered questionnaire was used as a tool for the study before and after the intervention. Intervention program was composed of small lectures and watching videos with coping maneuvers to be followed in case of any stress situation. Results: $64.7 \%$ and $22.4 \%$ of surveyed school teachers were having moderate and severe stress respectively. Bad behavior of students, long working hours and not enough salary were the common reported factors to cause a lot to severe stress among the sample. After introducing the stress management program, the percentage of teachers who have no stress increased from $12.9 \%$ to $32.9 \%$ and the percentage of those who have severe stress decreased from $22.4 \%$ to $5.9 \%$. In conclusion, the study revealed that one fifth of primary school teachers in Ismailia city perceived teaching as a severely stressful job. This study can be considered as a pilot study and further research need to be conducted to determine the most suitable stress management activities that suit our culture and local circumstances.
\end{abstract}

Key words: Stress, Management, Intervention, Teachers

\section{Introduction}

Teacher stress is a multifactorial phenomenon that spread globally irrespective to the level of development of country. Teacher stress is defined as a state of negative psychological effects experienced by teacher due to some aspects of their work ${ }^{(1)}$. These effects of work related stress (WRS) are experienced by people, when there is mismatch between pressures and demands of their work and their capabilities to $\operatorname{cope}^{(2)}$. Teaching and educational profession was rated as the second occupation with the highest prevalent rate of work related stress (2340 cases per 100,000$)$ after health care profession (2730 cases per $100,000)^{3}$. WRS may have a myriad of 
consequences and effects on health which encompass not only physical effects but also mental, behavioral and emotional effects ${ }^{4}$.

Teaching in primary school was perceived as a stressful job in many studies from different countries; Malaysia, Hong Kong, Zimbabwe, Nigeria, and UK ${ }^{(5-9)}$. National Institute for Occupational Safety and Health set a model for job stress composed of two main factors; stressful job conditions and individual and situational factors as primary cause of WRS), their interaction lead to risk of injury and illness ${ }^{10}$. For instance, some of the major sources of stress in school environment were student behavior, insufficient resources, heavy workload, relationship with colleagues, external school review, management and internal characteristics of teachers ${ }^{(10,6,7,8)}$. Although many studies described major sources of stress among teachers, It was suggested that researches on teacher stress should be replicated due to the local differences in sociocultural and economic environment between countries. Therefore, similar studies should be conducted in Egypt to explore the sources of stress among primary school teachers ${ }^{11}$.

Prevention and management of stress related work is not an easy task and no universal solution or technique can be applied for all countries or all jobs ${ }^{10}$. However, a comprehensive approach whereas both organizational and individual sources of stress are tackled concurrently is the ideal one. For instance reducing identified sources of stress at work together with providing teachers some skills for stress management such as relaxation techniques and time management will help. Briefly the steps for stress prevention at work include firstly, identification of the problem, secondly designing and implementing an intervention program then finally evaluation. Foreschle and Crews (2010) and Leung et al (2011) evaluated the impact of a school based stress management programs for reduction of teacher stress in middle and secondary school respectively. The authors conclude that offering stress management program within school is important however, several limitations were stated among them were inability of generalization of the results of these studies in other communities. Therefore, each country should follow the aforementioned steps in stress management taking into consideration the difference in sociocultural environment $^{(12-13)}$.

Primary school teachers in Egypt are facing many challenges such as shortage of facilities, low salaries and lack of training. In addition they are lacking basic psychological background to deal with students and their parents. The aim of this study was to measure the efficacy of a stress management program in lowering the level of stress among schools' teachers who suffers workrelated stress. And the specific objectives were to increase awareness of stress management techniques among teachers, to identify the occupational factors leading to stress among teachers and to find out the manifestations of stress and its levels among the teachers.

\section{Subjects and Methods}

A quasi-experimental design was used to test the effect of application of a stress management program among primary school teachers living in Ismailia city. Cluster sampling technique was used to choose the primary schools included in the study; urban area of Ismailia was 
divided into five sectors -Al Galaa, Gawad Hosny, Al sayeda Aisha, Alsalam and Al Nagah then from each sector two schools were picked by random sampling (ten schools) and finally, from each school 170 school teachers were selected randomly. Sample size was calculated using $95 \%$ confidence interval and $80 \%$ power of study. Prevalence of work-related stress among school teachers before introduction of stress management program was $30 \%$ while after introduction of program was $13 \%$, based on this the required number was 170 subjects.

\section{Inclusion and Exclusion criteria}

Participants are identified as teachers who were involved in the stress management program. Primary school teachers who were teaching for 3 years or more were included in the study. However, those who were working less than 3 years or working in the administration or suffering from any psychological problem or disease diagnosed by physicians, treatment with anti depressants, that may be associated with stress were excluded from the study.

\section{Tools of the study}

The instrument used was a selfadministered questionnaire adopted from Saul and Conboy (2001) and Fontana (2005) and translated into Arabic ${ }^{14-15}$. The questionnaire contained the following items; socio-demographic data such as name, sex, age, marital status and average years of teaching; sources of stress as perceived by teachers such as student factors (decreased students activity, careless about homework, student's needs special care and bad behavior), working environment (long working hours, little rest time, bad surroundings, parents, regular follow up and scientific competition) and management factors (not enough salary, changing educational policy, lack of educational resources and school manger); manifestations of stress in the form of physical (palpitation, easy fatigability, indigestion, loss of appetite, sweating (without effort, nausea), emotional feeling always busy, crying, intense reaction, feeling that you can do anything, loss of interest, inability to say no, loss of hope, hesitation and difficulty to take decision) and psychological effects (anxiety, inability to stop thinking, early morning awakening, cannot bear more of life's trouble, feeling carrying a lot of duties and insomnia). In addition, blood pressure was measured using a calibrated sphygmomanometer; and according to recommendations of the Seventh Report of the Joint National Committee of Prevention, Detection, Evaluation, and Treatment of High Blood Pressure (JNC VII), hypertension was defined as systolic pressure more or equal 140 and diastolic pressure more or equal 90.

Validation of the questionnaire was performed by conducting a pilot study using a structured interview to test reliability of the questions (by interviewing 15 teachers according to the inclusion \& exclusion criteria from the same area of the research) \& modifications were applied according to the comments of participants.

The degree of stress among teachers was assessed by adding up the response of participants to the different sources of stress mentioned in the self-administered questionnaire. The questionnaire uses Likert scale of five in the evaluation of 
responses whereby 1 mark was given for do not cause stress, 2 for causing little stress, 3 for causing some stress, 4 for causing a lot of stress and 5 for causing severe stress. Total scores were categorized into no stress (scores 15 or less) having moderate level of stress (scores=16-30), having severe level of stress (31 or more).

The intervention program (adapted from Bubb et al., 2004 and translated into Arabic) ${ }^{16}$ was conducted in three months and composed of two sessions (duration of each session 45 minutes). The sample was divided into seven groups of 25 teachers (one group only was 20) and each group was received the two sessions. The first session included small lecture (20 min.) and the topic of the lecture was "Management factors causing stress" and this included three steps, Step 1 Prioritizing tasks using an A, B, C approach, Step 2 planning each task according to SMART criteria to be easier to achieve and Step 3 implementation. The rest of session was practice on how to apply this maneuver. The second session was about three coping methods to manage stress: stress diary, physical relaxation techniques and rational positive thinking for anger management. Watching videos and brochures were used to facilitate the application of coping methods especially the stress diary and the physical relaxation techniques Post test was done using the same stress questionnaire four weeks later after finishing the coping program.

Before conducting the study, approval from the local director of Ministry of education and school directors was obtained. A written informed consent was taken from the teachers participating in the study. The participants have been informed that responding is voluntary and that they can refuse responding without stating any reason. Information confidentiality has been kept. The study was approved by the Ethical committee of Suez Canal University.

Statistical analysis was performed using the Statistical Package for Social Science (SPSS) version 16. Data were entered and coded into computer system. Data were first analyzed using descriptive statistics; means and standard deviation for quantitative data; frequencies and percentages for categorical data. Association between sociodemographic factors and level of stress was analyzed using Chi square test and Paired $\mathrm{T}$ test was used to detect the difference in the mean scores of stress before and after introducing the stress management program.

\section{Results}

Table 1 shows the sociodemographic characteristics of surveyed primary school teachers. The mean age of school teachers was 39.21 7.2 years with nearly half of them (54.1\%) between 35 and less than 45 years old. The majority of teachers were female $(82.9 \%)$ and married $(87.6 \%)$ as well as $45.9 \%$ of them have 3 or more children.

Table 2 shows that $64.7 \%$ and $22.4 \%$ of surveyed school teachers have moderate and severe stress respectively. None of the studied sociodemographic factors including age, gender, marital status, having children were significantly associated with the stress level among teachers.

Sources of stress as perceived by surveyed school teachers are presented in table 3. As regard the students' 
factors, bad behavior of students (79.4\%) followed by students, who need special care $(54.2 \%)$ were the most common factors that cause severe stress among the surveyed teachers. Concerning working factors, long working hours $(61.7 \%)$ and little rest times (48.3\%) were perceived by teachers to cause severe stress. For management factors, not enough salary $(67.6 \%)$ and changing educational policy $(61.8 \%)$ were the common reported factors to cause a severe stress among the sample.

Manifestations of stress among the studied teachers are presented in table 4 . For the physical effects, palpitation (74.1\%) followed by easy fatigability (69.4\%) and indigestion (51.2\%) were the commonest complaints among the sample. Feeling always busy (87.1\%) and crying $(67.7 \%)$ were the commonest emotional complaints in the sample. Psychologically, anxiety (84.7\%) followed by inability to stop thinking (76.55) was the commonest reported complaints.

After introducing the stress management program, the percentage of teachers, who have no stress increased from $12.9 \%$ to $32.9 \%$, and the percentage of those, who have severe stress decreased from $22.4 \%$ to $5.9 \%$ (Table 5). There was a statistical significant difference ( $p$ value $<0.001$ ) in the mean score of stress before (22.9 \pm 7.4$)$ compared to after $(18.0 \pm 5.9)$ introducing the stress management program.

\section{Discussion}

The current study revealed that the majority of primary school teachers in Ismailia Governorate perceived that teaching is stressful occupation with level ranging from moderate to severe. Furthermore, none of the studied sociodemographic characteristics were significant associative factors with level of stress. Results also indicate that participation in the stress management program was associated with a decrease in mean score of level of stress among the surveyed sample.

The findings of this study revealed that one fifth $(22.4 \%)$ of the surveyed school teachers in Ismailia governorate perceived that teaching is severe stressful occupation. Accordingly, those teachers are exposed to incapacitating stress that could have serious consequences on their health and their work productivity and efficacy as well as students' learning ${ }^{17-18}$. Higher job stress is expected in countries with a lower degree of economic development as in Egypt. The prevalence of severe stress in the current study was three times higher (7.7\%) than that reported among Malayan primary school teachers ${ }^{7}$, but was three times lower $(65 \%)$ than that reported among Zimbabwean primary school teachers ${ }^{19}$. The discrepancy between the current study and the latter two studies could be related to methodological differences or socioeconomic differences. For instance, the current study focused on urban school teachers, however in Denhere (2011), the studied sample was rural school teachers with lower socioeconomic standard as living in houses with no tapped water or electricity $^{19}$. In contrast the lower prevalence of severe stress among Malayan teachers may be explained by cultural difference as Malay people tend to overlook their psychological problems or better salary (762 US dollars), however, the average salary of Egyptian primary school teacher was approximately three times lower (281 US dollars) according to the report of 
Middle East and North Africa Programme, Chatham House ${ }^{(20,7)}$.

None of the studied sociodemographic factors including age, gender, marital status, having children were significantly associated with the stress level among teachers. A limitation of this study was job related variables such as job status, job experience; number of students per class, monthly income, teaching hours per week was not examined. This would help to have a full picture of factors that may affect the level of stress among the studied sample.

In the current study, gender was not significantly associated with level of stress. Previous studies

also have shown no relation between gender and level of stress among school teachers $^{(7,19,8,21)}$. However, Inconsistent findings was found in the literature regarding gender and level of stress; It was found that female teachers reported more stress than their male counterparts $^{(22)}$, however, it was found that male teachers reported more stress than female teachers ${ }^{(23-24)}$.

Identification of main sources of stress among school teachers will have great repercussions for intervention as their improvement or lessening could lead to corresponding changes in levels of stress ${ }^{(8)}$. This study revealed that bad behavior of students, not enough salary, changing educational policy and long working hours were the major source of stress to the participants. Similar findings by previous studies found that student misbehavior, teaching environment, heavy workload and time pressure are among the major sources of stress among primary school teachers in different areas such as Malaysia, Hong Kong and Nigeria ${ }^{(7,6,8)}$.
The current study also showed that physical, emotional and psychological complaints were prevalent among participants. Also other studies (Hanif et al. 2011), showed that teachers may experience similar diverse complaints ${ }^{18}$, however, Olaitan et al. 2010 from Nigeria physical complains were the leading manifestations among participants $^{(6)}$.

After introducing the stress management program, there were a significant decrease in the prevalence of stress and mean score of stress among the participants after the intervention compared to those before introduction of intervention program. Other studies have shown also that offering stress management within the school setting can reduce the level of stress and improve the quality of life ${ }^{(2,25)}$. Also, Leung et al. 2011 found that applying a brief cognitive behavioral stress management program for secondary school teachers helped in reducing the work related stress among those teachers. Although, in the current studies and others, the root causes of stress among school teachers were not tackled, it seems that stress management programs helped in reducing the level of stress among participants ${ }^{(13)}$.

In conclusion, the study revealed that one fifth of primary school teachers in Ismailia governorate perceived teaching as a severely stressful job. Level of stress among Egyptian primary school teachers is not as high as other African countries due to specific work conditions. This is something need to be investigates more in future research as there seem to be some protective factors against stress that need to be identified and enhanced through appropriate support mechanisms. The current study 
also highlights the major sources of stress among teachers which will serve as a guide for the government and related organizations such as ministry of education to set policies and strategies that help to reduce the level of stress among teachers. Finally, the current study also showed that applying some educational stress management strategies can help in reducing stress level among teachers. This study can be considered as a pilot study and further research need to be conducted to determine the most suitable stress management activities that suit our culture and local circumstances and how this can be incorporated within schools to help teachers coping with work related problems.

\section{Limitations of the study:}

Some Limitations can be noticed in this study. First, self- report tool was used in data collection and this may be subjected to recall bias. Second, both the duration of intervention and the period of follow up were short and consequently long term effects cannot be assessed. Finally, no control group and therefore the efficacy of the stress management program cannot be assessed.

\section{References}

1) Yriacou C. Teacher stress, Directions for future research. Educational reviews, 53 (1), 2001; 7-35.

2) WHO. Stress management program, 2014. Available at http://www.who.int/occupational_heal th/publications/en/oehstress.pdf

3) Health and Safety Executive (HSE)a: Stress and Psychological Disorders in Great Britain 2013
Available at http://www.hse.gov.uk/statistics/causdis/ stress/stress.pdf, accessed at 17 Feb 2014.

4) Health and Safety Executive (HSE)b: what is stress? Available at http://www.hse.gov.uk/stress/furtheradvi ce/whatisstress.htm accessed at $17 \mathrm{Feb}$ 2014.

5) Smith A, Johal S, Wadsworth E, Smith GD and Peters T. The scale of occupational stress the Bristol stress and health at work safety. 265/2000. Health and Safety Executive Books (Ed.) published by Norwish, crown her majesty Stationary office, 2000; Pp. 1319.

6) Olaitan OL, Oyerinde OO, Obiyemi O. and Kayode O. O. Prevalence of job stress among primary school teachers in South-west, Nigeria. African Journal of Microbiology Research, 2010; 4 (5), 339-342.

7) Samad, Nurul Izzah Abdul, Zailina Hashim, Saidi Moin, Haslinda Abdullah. Assessment of Stress and Its Risk Factors among Primary School Teachers in the Klang Valley, Malaysia. Global Journal of Health Science Vol. 2, No. 2; October 2010. 163-171

8) Chan A H.S., Chen $K$ and Chong EYL (2010). Work Stress of Teachers from Primary and Secondary Schools in Hong Kong. Proceedings of the international nmulticonference of engineers and computer scientists. Vol III.

9) Denhere C (2011). A Don Quizote fighting windmills: A study of teachers' imagined stress in the teaching 
profession. Journal of African Studies and Development , 3(9), 171-175.

10) Sauter S, Lawrence $M$, Michael $C$ (1999). Stress at work, DHHS (NIOSH) Publication, pp 99-101.

11) Kyriacou C and Chien PY (2014). Teacher stress in Taiwanese primary schools. Journal of Educational Enquiry, 5(2), 86-104.

12) Froeschle JG and Crews CR (2010). The efficacy of a collaborative stress management program for teachers. Retrieved from

http://counselingoutfitters.com/vistas/vis tas10/Article_71.pdf Article 71.

13) Leung SSK, Chiang VCL, Chui YY, Mak, YW and Wong DFK. A brief cognitive-behavioral stress management program for secondary school teachers. European Journal of Experimental Biology, 2011, 3(4):188193.

14) Saul N J, Conboy J (2001) "A stress management course to prevent teacher distress". International Journal of Educational Management, Vol. 15 Iss: 3, pp.131 - 137

15) Fontana D. (2005). Professional stress scale. Adapted from Managing Stress by David Fontana (1989), The British Psychological Society and Routledge Ltd., Leicester, England. www.lallicareclinic.ca/depression_profe ssional_life_stress_scale.html.

16) Bubb $S$ and Earley $P$ (2004). Managing Teacher WorkloadWork-Life Balance and Wellbeing. publishers.Paul Chapman Publishing A SAGE
Publications Company1 Oliver's Yard55 City Road London.Library of Congress Control Number:2004107216. pages, 1130

17) Chan DW (2010). Teacher burnout revisited: introducing positive intervention approaches based on gratitude and forgiveness. The Educational Research Journal, 25(2), 165-186.

18) Hanif $R$, Tarik $S$ and Nadeem $M$ (2011). Personal and Job Related Predictors of Teacher Stress and Job Performance among School Teachers. Pak. J. Commer. Soc. Sci. 5 (2), 319329.

19) Denhere C. Stress among Primary school teachers in Matabeleland North Region. 2011, Journal of African Studies and Development Vol 3(8)

20) Abdul Hadi A, Naing NN, Daud A, Nordin R, and Sulong MR (2009). Prevalence and factors associated with stress among secondary school teachers in kota bharu, kelantan, malaysia. Southeast Asian J Trop Med Public Health, 40(6), 1359-1370.

21) Kalyva E (2013). Stress in Greek Primary Schoolteachers Working Under Conditions ofFinancial Crisis. Europe's Journal of Psychology, 9(1), 104-112.

22) Kumar IA, Wani ZA and Parrey AA (2013). Occupational Stress among Male and Female Elementary School Teachers of District Pulwama. International Journal of Scientific and Engineering Research, 4 (4), 934-941.

23) Duyilemi BO (1992). Determinants and sources of occupational stress among Nigerian secondary school 
teachers. Nigerian Journal of Education Foundations, 3, 26-37.

24) Borg MG. and Riding RJ. (1991). Occupational stress and satisfaction in teaching. British. Educational Research Journal, 17(3), 263-281.
25) Mohammad M, Mahmoodabad S S M, Zadehe DS, Barkhordari A, Hosaini F, Kaveh M H, Maleh A S and Rahiminegad M (2013). The study of the effect of stress management program on transactional model constructs in Yazd teachers of primary schools. European Journal of Experimental Biology,3(4):188-193 
Table 1: Sociodemographic factors of surveyed primary school teachers.

\begin{tabular}{|l|l|}
\hline Sociodemographic factors & $\begin{array}{l}\text { N (170) } \\
\mathbf{n}(\%)\end{array}$ \\
\hline Age groups: & \\
$25-$ & $33(19.4)$ \\
$35-$ & $92(54.1)$ \\
$45-55$ & $45(26.5)$ \\
Mean \pm SD & $39.2 \pm 7.2$ \\
\hline Gender: & \\
Male & $29(17.1)$ \\
Female & $141(82.9)$ \\
\hline Marital Status: & \\
Married & $149(87.6)$ \\
Divorced/widow & $9(5.3)$ \\
Single & $12(7.1)$ \\
\hline Having children: & \\
None & $20(11.8)$ \\
1-2 & $72(42.4)$ \\
3 or more & $78(45.9)$ \\
\hline
\end{tabular}


Table 2: Prevalence of stress and association between degree of stress and sociodemographic factors.

\begin{tabular}{|c|c|c|c|c|c|}
\hline \multirow[t]{2}{*}{ Sociodemographic factors } & \multicolumn{3}{|c|}{$\begin{array}{l}\text { Level of stress } \\
\mathbf{N}=170\end{array}$} & \multirow[t]{2}{*}{$\mathbf{X}^{2}$} & \multirow[t]{2}{*}{ P value } \\
\hline & $\begin{array}{l}\text { No stress } \\
\text { n }(\%)\end{array}$ & $\begin{array}{l}\text { Moderate } \\
\text { n }(\%)\end{array}$ & $\begin{array}{l}\text { Severe } \\
\mathrm{n}(\%)\end{array}$ & & \\
\hline $\begin{array}{l}\text { Age (years): } \\
25- \\
35- \\
45-55 \\
\end{array}$ & $\begin{array}{l}4(10.8) \\
12(14.4) \\
6(11.6)\end{array}$ & $\begin{array}{l}22(59.5) \\
57(63.3) \\
31(72.1) \\
\end{array}$ & $\begin{array}{l}11(29.7) \\
20(22.2) \\
7(16.3)\end{array}$ & 2.5 & 0.64 \\
\hline $\begin{array}{l}\text { Gender: } \\
\text { Male } \\
\text { Female }\end{array}$ & $\begin{array}{l}7(24.1) \\
15(10.6)\end{array}$ & $\begin{array}{l}17(58.6) \\
93(66.0)\end{array}$ & $\begin{array}{l}5(17.2) \\
33(23.4)\end{array}$ & 3.1 & 0.14 \\
\hline $\begin{array}{l}\text { Marital Status: } \\
\text { Married } \\
\text { Divorced/widow } \\
\text { Single }\end{array}$ & $\begin{array}{l}20(13.4) \\
1(11.1) \\
1(8.3)\end{array}$ & $\begin{array}{l}96(64.4) \\
7(77.8) \\
7(58.3)\end{array}$ & $\begin{array}{l}33(22.1) \\
1(11.1) \\
4(33.3)\end{array}$ & 1.7 & 0.79 \\
\hline $\begin{array}{l}\text { Having children: } \\
\text { None } \\
1-2 \\
3 \text { or more } \\
\end{array}$ & $\begin{array}{l}1(5.0) \\
12(16.7) \\
9(11.5) \\
\end{array}$ & $\begin{array}{l}11(55.0) \\
48(66.7) \\
51(65.4)\end{array}$ & $\begin{array}{l}8(40) \\
12(16.7) \\
18(23.1) \\
\end{array}$ & 6.1 & 0.20 \\
\hline Total & $22(12.9)$ & $110(64.7)$ & $38(22.4)$ & & \\
\hline
\end{tabular}


Table 3: Sources of stress as perceived by surveyed primary school teachers.

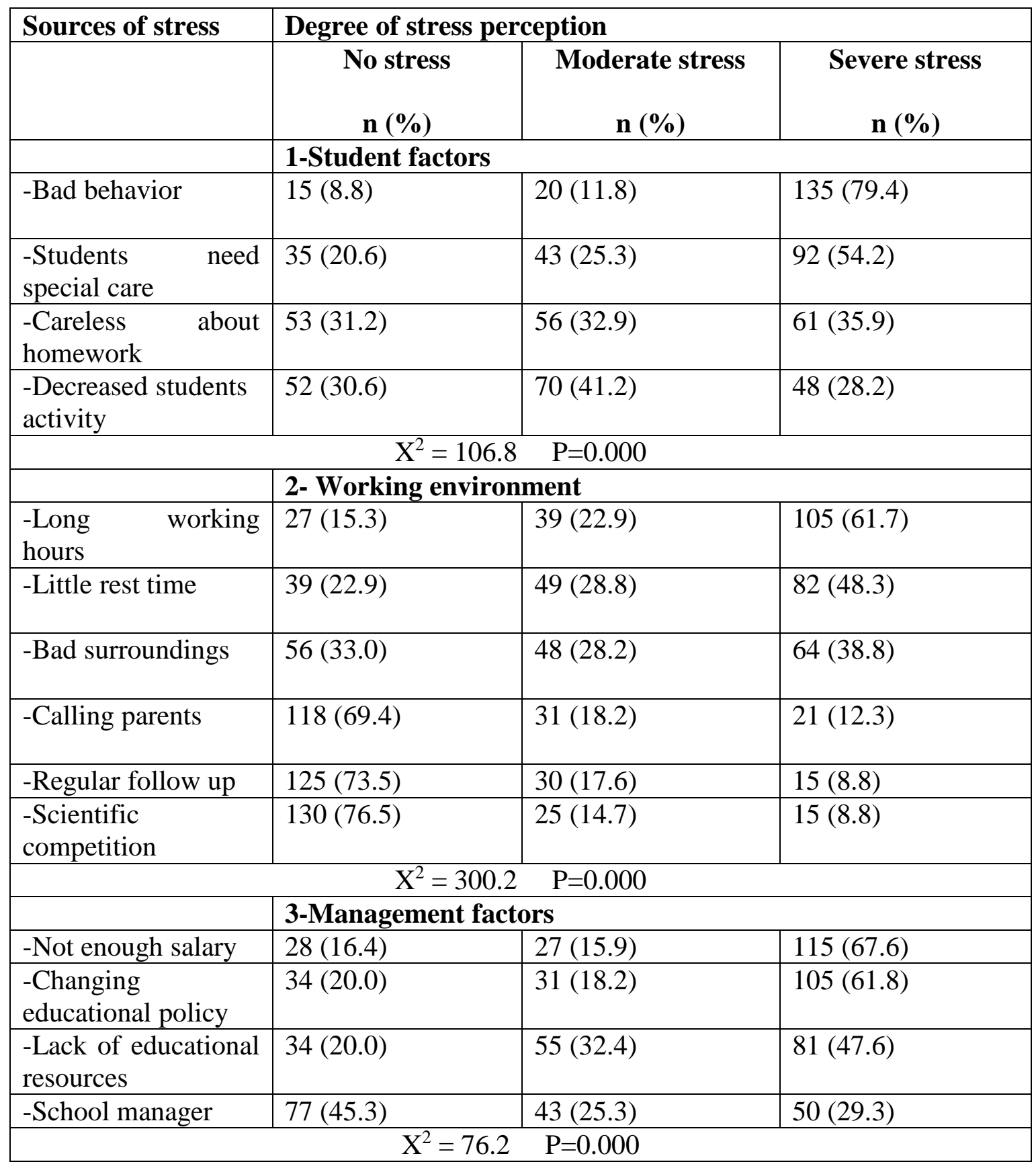


Table 4: Manifestation of stress among surveyed primary school teachers.

\begin{tabular}{|l|l|l|l|l|}
\hline & \multicolumn{2}{l|}{ Yes* } & \multicolumn{2}{l|}{ No } \\
\hline & $\mathbf{n}$ & Percent & $\mathbf{n}$ & Percent \\
\hline \multicolumn{1}{|l|}{ 1- Physical effects } & & & & \\
\hline -Palpitation & 126 & 74.1 & 44 & 25.9 \\
\hline -Easy fatigability & 118 & 69.4 & 52 & 30.6 \\
\hline -Indigestion & 87 & 51.2 & 83 & 48.8 \\
\hline -Loss of appetite & 68 & 40.0 & 102 & 60.0 \\
\hline -Sweating without effort & 51 & 30.0 & 119 & 70.0 \\
\hline -Fainting or nausea & 47 & 27.7 & 123 & 72.3 \\
\hline -Hypertension & 26 & 15.3 & 144 & 84.7 \\
\hline \multicolumn{1}{|c|}{ - Emotional effects } & & & & \\
\hline -Feeling always busy & 148 & 87.1 & 22 & 12.9 \\
\hline -Crying & 115 & 67.7 & 55 & 32.3 \\
\hline -Intense reaction & 88 & 51.8 & 82 & 48.2 \\
\hline -Feeling that you can do anything & 87 & 51.2 & 83 & 48.8 \\
\hline -Loss of interest & 77 & 45.3 & 93 & 54.7 \\
\hline -Inability to say no & 67 & 39.4 & 103 & 60.6 \\
\hline -Loss of hope & 64 & 37.6 & 106 & 62.4 \\
\hline -Hesitation & 59 & 34.7 & 111 & 65.3 \\
\hline -Difficult to take decision & 57 & 33.5 & 113 & 66.5 \\
\hline 3- Psychological effects & & & & \\
\hline -Anxiety & 144 & 84.7 & 26 & 15.3 \\
\hline -Inability to stop thinking & 130 & 76.5 & 40 & 23.5 \\
\hline -Early morning awakening & 127 & 74.7 & 43 & 25.3 \\
\hline -Cannot bear more of life's troubles & 121 & 71.2 & 49 & 28.8 \\
\hline -Feeling carrying a lot of duties & 121 & 71.2 & 49 & 28.8 \\
\hline -Insomnia & 110 & 64.7 & 60 & 35.3 \\
\hline
\end{tabular}

*Multiple answers 
Table 5: Degree of stress among surveyed primary school teachers before and after introducing the stress management program.

\begin{tabular}{|c|c|c|c|c|}
\hline & $\begin{array}{l}\text { Before } \\
(\mathrm{N}=170)\end{array}$ & & $\begin{array}{l}\text { After } \\
(\mathbf{1 7 0}) \\
\end{array}$ & \\
\hline & $\mathbf{n}$ & Percent & n & Percent \\
\hline -No Stress & 22 & 12.94 & 56 & 32.94 \\
\hline $\begin{array}{l}\text {-Moderate } \\
\text { Stress }\end{array}$ & 110 & 64.70 & 104 & 61.17 \\
\hline -Severe Stress & 38 & 22.36 & 10 & 5.89 \\
\hline Mean \pm SD & \multicolumn{2}{|l|}{$22.9 \pm 7.4$} & \multicolumn{2}{|l|}{$18.0 \pm 5.9$} \\
\hline Paired $t$ test & \multicolumn{4}{|l|}{13.094} \\
\hline P value & \multicolumn{4}{|l|}{$<0.001$} \\
\hline
\end{tabular}

